\title{
LA RESTAURACIÓN ABSOLUTISTA Y EL PODER MUNICIPAL: APROXIMACIONES A 1814 DESDE EL SUROESTE ANDALUZ
}

\author{
JOSÉ SALDAÑa FERNÁNDEZ ${ }^{1}$ \\ UNIVERSIDAD DE VALPARAÍSO
}

RESUMEN: Los últimos tiempos de la Guerra de la Independencia resultaron muy reveladores sobre el clima de tensiones y contrariedades que se había abierto entre las filas anti-napoleónicas. El difícil equilibrio que había definido las relaciones entre liberales y absolutista se rompía con el retorno de Fernando VII en 1814. El poder municipal, afectado por intensas transformaciones desde 1808, no quedaba al margen del proceso de reversión emprendido desde los sectores absolutistas. En este sentido, el artículo ahonda, a partir de los ejemplos proporcionados por el suroeste andaluz, en la realidad concreta de un proceso de cambio que no resultaba ni homogéneo ni lineal, y que en conjunto no pudo abstraerse del reajuste político-social y del nuevo equilibrio de fuerzas generado durante los años precedentes.

PALABRAS CLAVE: Restauración, Municipios, Fernando VII, Contrarrevolución, Guerra de la Independencia

\section{ABSOLUTIST RESTORATION AND LOCAL POWER: AN APPROACH TO 1814 FROM SOUTHWEST ANDALUSIA}

\begin{abstract}
The final months of the Peninsular War were very revealing about climate of tensions and setbacks opened among the anti-Napoleonic ranks. The difficult balance that had defined the relations between liberals and absolutists was broken by the return of Ferdinand VII in 1814. The local power, affected by intense transformations from 1808, was not outside the process of reversion undertaken by the absolutist groups. In this sense, the article explores, through the examples provided by the southwest of Andalusia, a process of change that was neither homogeneous nor lineal, a process that was not able to avoid socio-political realignment and new power balance generated during the previous years.
\end{abstract}

KEYWORDS: Restoration, Municipalities, Fernando VII, Counterrevolution, Peninsular War Recibido: 05/12/2016/Aceptado: 19/12/2016

\footnotetext{
1 Este trabajo forma parte del proyecto de investigación HAR2015-65991-P: "Entre revolución y contrarrevolución. Ciudades, espacio público, opinión y politización (1789-1888)", financiado por el Ministerio de Economía y Competitividad y el Fondo Europeo de Desarrollo Regional (FEDER).
} 
La Guerra de la Independencia resultaría crucial para el desarrollo de la contemporaneidad en España. Y lo sería tanto por la complejidad y alcance de los cambios implementados entre 1808 y 1814 como por la proyección que algunos de sus componentes alcanzarían, de manera directa o diferida, a partir de esa fecha. La identificación de aquel episodio con el inicio de un nuevo tiempo o su continua referencialidad a lo largo de los dos siglos siguientes dan buena cuenta, por tanto, de su trascendencia. En este escenario habría que destacar, por ejemplo, su posición central dentro de las narrativas sobre la modernidad en España. Y es que la guerra, según cabe subrayar, vino acompañada de innovaciones más o menos profundas en ámbitos como el de la configuración del poder y la práctica política, lo que ya fue caracterizado por sus mismos protagonistas bajo el signo de la revolución, y que sigue encontrando además, doscientos años después, nuevos campos de atención y desarrollo.

En fin, no estamos ante una cuestión cerrada por más que se hayan ampliado y diversificado los focos de análisis. Es cierto que se ha recorrido un interesante camino en torno a asuntos como, por ejemplo, la puesta en marcha de ciertas prácticas de sufragio avanzadas, la ampliación del espacio de participación pública, la densificación de la escena política o el diseño y el aprendizaje de una nueva cultura de concurrencia y gestión del poder². En palabras de Emilio La Parra, "la guerra de los españoles contra Napoleón fue un factor de aceleración del tiempo histórico, provocó cambios en todos los ámbitos (institucionales, geográficos y humanos), innovó el lenguaje político, abrió de forma rápida y amplia el espacio público y marcó la ruptura con el Antiguo Régimen”3. Ahora bien, tampoco es menos cierto que quedan muchas cuestiones por concretar en relación a los contornos y los alcances precisos del proceso de politización activado durante aquellos años. Entre otros, sobre las implicaciones, efectos o recorridos de dicho proceso en coyunturas posteriores marcadas por la vuelta, de manera más o menos acentuada, al marco político del Antiguo Régimen.

Todo ello además desde una mirada que trascienda el general protagonismo concedido a los espacios centrales y que, por tanto, se acerque a este fenómeno

\footnotetext{
2 POSADA CARBÓ, Eduardo: "Sorpresas de la historia. Independencia y democratización en Hispanoamérica”, Revista de Occidente, 326-327 (2008), pp. 109-125; DEMÉLAS, Marie-Danielle y GUERRA, François-Xavier: Los orígenes de la democracia en España y América. El aprendiraje de la democracia representativa, 18081814, Lima, Fondo Editorial del Congreso del Perú/Oficina Nacional de Procesos Electorales, 2008; LUIS, Jean-Philippe: "Cuestiones sobre el origen de la modernidad política en España (finales del siglo XVIII1868)", Jerónimo Zurita, 84 (2009), pp. 247-276; RÚJULA, Pedro: "La densificación del universo político popular durante la Guerra de la Independencia”, en P. Rújula y J. Canal (ed.), Guerra de ideas. Política y cultura en la España de la Guerra de la Independencia, Zaragoza/Madrid, Institución Fernando el Católico/Marcial Pons, 2012, pp. 173-190; MAESTROJUÁN, Javier: "Guerra de la Independencia y comunidad urbana. La crisis de un modelo secular”, Jerónimo Zurita, 88 (2013), pp. 233-258.

3 LA PARRA, Emilio, "Presentación” [Dossier: La Guerra de la Independencia], Ayer, 86 (2012), p. 14.
} 
considerando la disparidad de escenarios o la multiplicidad de los protagonistas. Esto implica, entre otras cuestiones, la incorporación al análisis de los espacios locales de ámbito rural, aquellos en los que se desenvolvía por entonces la cotidianeidad de la mayor parte de la población. De hecho, durante el contexto específico de 1808 a 1814 los ayuntamientos no solo atrajeron la atención de los nuevos poderes superiores -tanto fernandinos como josefinos- en aspectos relacionados con su conformación, composición, organización o funciones ${ }^{4}$, sino que para la mayor parte de la población se erigieron en los instrumentos más visibles y tangibles del nuevo tiempo traído por la guerra, dando forma y contenido a la recién estrenada ciudadanía política ${ }^{5}$. Una circunstancia acrecentada además por el hecho de que los órganos políticos del municipio asumieron entonces un destacado protagonismo en la gestión de los elevados requerimientos y suministros con los que los pueblos tenían que contribuir para el mantenimiento de los ejércitos. Como ha subrayado Pedro Rújula, el telón de fondo de la guerra trajo consigo, en el campo específico de la política, "un aprendizaje profundo y vital que surgía del contacto con las exacciones, con la violencia, con la destrucción o con la lucha por la supervivencia" ${ }^{\prime 6}$.

El suroeste andaluz daba buena cuenta del dinamismo y la complejidad que alcanzaría durante la guerra el escenario político a escala municipal, ya sea, por ejemplo, en el terreno de la autonomía y la reafirmación local frente al marco señorial tradicional, o ya sea sobre las nuevas prácticas políticas implementadas en torno a la conformación y la

\footnotetext{
4 Un análisis general en torno a los ayuntamientos tanto josefinos como fernandinos en: CASTRO, Concepción de: La revolución liberal y los municipios españoles (1812-1868), Madrid, Alianza, 1979; GARCÍA FERNÁNDEZ, Javier: El origen del municipio constitucional: autonomía y centralización en Francia y en España, Madrid, Instituto de Estudios de la Administración Local, 1983; MERCADER RIBA, Juan: José Bonaparte Rey de España (1808-1813). Estructura del Estado Español Bonapartista, Madrid, Consejo Superior de Investigaciones Científicas/Instituto de Historia "Jerónimo Zurita", 1983; MERCHÁN FERNÁNDEZ, Carlos: Gobierno municipal y administración local en la España del Antiguo Régimen, Madrid, Tecnos, 1988; MUÑOZ DE BUSTILLO ROMERO, Carmen: Bayona en Andalucia: el Estado Bonapartista en la Prefectura de Xerez, Sevilla/Madrid, Junta de Andalucía/Centro de Estudios Constitucionales, 1991; CARASA SOTO, Pedro (coord.): Ayuntamiento, Estado y Sociedad. Los poderes municipales en la España contemporánea, Valladolid, Ayuntamiento de Valladolid, 2000; DÍAZ TORREJÓN, Francisco Luis: Osuna Napoleónica (1810-1812). Una villa andaluza y su distrito durante la ocupación francesa, Sevilla, Fundación Genesian, 2001; GARCÍA FERNÁNDEZ, Javier: "El municipio en los orígenes del constitucionalismo español. Notas sobre la génesis de la organización municipal a través de tres modelos constitucionales", en El municipio constitucional. II Seminario de Historia de la Administración, Madrid, Instituto Nacional de Administración Pública, 2003, pp. 47-55; ORDUÑA REBOLLO, Enrique: Municipios y provincias: historia de la organización territorial española, Madrid, Federación Española de Municipios y Provincias/Instituto Nacional de Administración Pública/Centro de Estudios Políticos y Constitucionales, 2003.

${ }^{5}$ Desde una perspectiva más amplia no puede obviarse la centralidad que ocuparía el espacio local a lo largo de todo el siglo XIX, constituyéndose en el ámbito primario y natural en el que se desarrollaría buena parte de la vida política y social de sus habitantes. BURDIEL, Isabel y ROMEO, María Cruz: "Viejo y nuevo liberalismo en el proceso revolucionario", en P. Preston e I. Saz (eds.), De la revolución liberal a la democracia parlamentaria. Valencia (1808-1975), Madrid/Valencia, Biblioteca Nueva/Universitat de València, 2001, pp. 7591; GUERRA, François-Xavier: "De la política antigua a la política moderna. La revolución de la soberanía", en F. X. Guerra, Los espacios públicos en Iberoamérica. Ambigüedades y problemas. Siglos XVIII-XIX, México, Fondo de Cultura Económica, 1998, pp. 109-139.

${ }^{6}$ RÚJULA, Pedro: “La densificación del universo político...”, p. 189.
} 
gestión del poder dentro del municipio. En todo caso, esta riqueza y diversidad de situaciones y experiencias no podría entenderse, al menos en toda su dimensión, sin considerar las características del espacio político de fondo, tanto por las circunstancias jurisdiccionales preexistentes como por la redefinición del sistema fronterizo que trajo consigo la ocupación francesa. Además de la proyección que tenía en aquel escenario el marco señorial habría que considerar que junto a la raya tradicional que marcaba la división entre los dos reinos peninsulares se llegó a constituir entre 1810 y 1812 una nueva frontera menos visible y más cambiante, aunque no por ello menos efectiva, la que marcaba la separación entre las tierras ocupadas por los franceses frente a esas otras que quedaban fuera de su control permanente. En líneas generales, los pueblos situados entre los ríos Odiel y Guadiana no fueron ocupados de manera continuada y quedaron sujetos, aunque no sin obstáculos, al marco gubernativo trazado por los poderes fernandinos.

En teoría ello supondría, entre otras cuestiones, la proyección de modelos distintos de gestión comunitaria de los recursos. En la práctica, en cambio, este doble escenario compartía algunos atributos y tendencias de fondo, particularmente respecto a la apertura de espacios de representación vecinal más amplios y dinámicos. Por ejemplo, en la villa de Huelva, situada dentro de los cauces marcados por las autoridades bonapartistas, se conformaba en julio de 1811 una Junta de subsistencia como parte de un proceso que terminaba sobrepasando el marco preciso y cerrado de su ayuntamiento: de hecho, los miembros del mismo, acompañados de algunos vecinos, "los más condecorados y pudientes", convenían la celebración de una convocatoria abierta a los “más pudientes", los cuales, una vez reunidos en un número superior a la treintena, eligieron a los miembros de la nueva institución. Por su parte, en la villa de Cartaya, situada en el ámbito de adscripción fernandino, la Junta de permanencia creada en octubre de 1811 para atender a los suministros, contribuciones, repartimientos y demás cuestiones sobre este particular sería el resultado de las decisiones adoptadas por el "común de los vecinos", que se habían reunido en un cabildo abierto -en el que participaron los miembros del ayuntamiento y un crecido número de vecinos- y decidido tanto la formación de la junta, como los miembros que formaban parte de la misma. La Junta de subsistencia creada en Villanueva de los Castillejos en julio de 1812 -también dentro del marco fernandino- presentaba en cambio un perfil institucional muy diferente: el ayuntamiento citaba a los principales del vecindario y después de conferenciar sobre el particular, designaban en común acuerdo a los miembros que debían formar parte de la nueva institución. No obstante, a pesar del formato restringido que se empleaba, la naturaleza del ayuntamiento que le daba cobertura 
le confería unos rasgos legitimadores que no estaban presentes en otros casos similares, ya que ese cabildo se había compuesto siguiendo un procedimiento abierto impulsado desde la misma comunidad local y que contempló la participación de todos sus vecinos sin distinción alguna ${ }^{7}$.

En efecto, los ayuntamientos también se verían afectados entonces por el proceso de aperturismo político y social de fondo. Algunos de los cabildos del suroeste andaluz se mostraron muy activos y dinámicos a la hora no solo de alcanzar mayores cotas de autonomía y soberanía comunitaria, sino de proyectar nuevas fórmulas de compromiso y participación que incorporasen a amplios sectores de la comunidad, extendiendo así la base social sobre la que tradicionalmente se apoyaban. Desde esta perspectiva, los cambios más importantes se dieron desde la segunda mitad de 1811. En el escenario bonapartista había que destacar, por ejemplo, lo ocurrido en Gibraleón, cuyo ayuntamiento de 1812 se conformaba siguiendo un sistema de elección abierto según aparecía recogido en la normativa trasladada desde Sevilla: en todo caso, la decisión última correspondía a las autoridades superiores, detectándose algunos desajustes entre el resultado de la elección vecinal y el esquema de municipalidad confeccionado finalmente por los poderes superiores. Y en el ámbito fernandino podría destacarse los casos de Villanueva de los Castillejos y El Almendro, que montaron sendos ayuntamientos para 1812 a partir de procesos de elección abiertos que habían tomado cuerpo por iniciativas de miembros de sus respectivas comunidades locales, destacando, al menos en el primer caso, el protagonismo de los sectores sociales tradicionalmente alejados del poder ${ }^{8}$.

En líneas generales, el enfrentamiento político por la incorporación o el control de los órganos de poder municipal adquiría una nueva dimensión tras la puesta en marcha de los nuevos ayuntamientos constitucionales. De hecho, durante esta última fase quedaba esbozada una práctica política más compleja y dinámica que disponía de dos escenarios básicos de desarrollo: por un lado, la lucha partidista con anterioridad a las elecciones, con la vista puesta en alcanzar cierto espacio de poder interno; por otro, la confrontación en el interior de la corporación a lo largo de su etapa de gobierno entre miembros que respondían a fidelidades grupales diferentes y a intereses distintos?

\footnotetext{
${ }^{7}$ SALDAÑA FERNÁNDEZ, José: Pueblo, nación y ciudadanía durante la Guerra de la Independencia: la frontera sur hispano-portuguesa en los orígenes de la contemporaneidad (1808-1814), Tesis Doctoral, Universidad de Huelva, 2014. ${ }^{8}$ SALDAÑA FERNÁNDEZ, José: "Más allá de Cádiz: la experiencia como aprendizaje en el ámbito político municipal (1810-1814)", en G. Butrón Prida y A. Ramos Santana (eds.), Cádiæz escuela política: hombres e ideas más allá de 1814, Madrid, Sílex, 2016, pp. 213-240.

9 SALDAÑA FERNÁNDEZ, José: Pueblo, nación y ciudadanía...
} 
Pues bien, esa nueva y rica experiencia de la guerra, con su impronta en el campo de la innovación y el aprendizaje políticos, podría resultar clave a la hora de explicar algunos de los acontecimientos y actuaciones de los siguientes años. $\mathrm{Y}$ es que si bien es cierto que, según refiere Emilio La Parra, durante la Restauración "el pensamiento y la actitudes reaccionarias alcanzaron en España tal hegemonía, que eliminaron de la esfera pública cualquier alternativa" 10 , no lo es menos, como sostiene Pedro Rújula, que "más allá de la voluntad de las antiguas élites para encaramarse de nuevo al poder, basada en la reivindicación de una legitimidad histórica y en la vuelta a patrones políticos y sociales anteriores, la realidad era que había que empezar de nuevo, hacer balance de daños y tratar de recomponer el mundo con los materiales del presente, que no eran, ni mucho menos, los de unos años atrás" ${ }^{11}$. No parece, por tanto, que la vuelta al modelo anterior a la guerra pudiese abstraerse plenamente de las circunstancias socio-políticas puestas en marcha desde mayo de 1808. Otra cosa distinta sería calibrar el alcance preciso que tendría aquella experiencia política revolucionaria para el nuevo escenario construido a partir de 1814. En fin, mucho queda aún por recorrer respecto a la nueva realidad abierta tras la restauración fernandina, en particular desde la perspectiva de los ámbitos municipales ${ }^{12}$. Las siguientes páginas pretenden precisamente un acercamiento al proceso de reinstauración del absolutismo tomando como referencia lo experimentado en algunos pueblos del suroeste ${ }^{13}$. Y lo hace sin obviar la compleja realidad vivida durante los años de la guerra, marco a partir del cual sus propios protagonistas debieron de interpretar la nueva experiencia vital que se les presentaba tras la vuelta de ElDeseado.

\footnotetext{
${ }^{10}$ De hecho, "hubo un claro propósito de suprimir mediante la represión o el silencio a quienes mantenían las ideas de la época revolucionaria anterior e, incluso, de eliminarlos físicamente". LA PARRA, Emilio: "La restauración de Fernando en 1814", Historia Constitucional, 15 (2014), pp. 205-222, cit. p. 207.

11 RÚJULA, Pedro: "Presentación. Recomponer el mundo después de Napoleón. 1814 y las restauraciones", Pasado y Memoria. Revista de Historia Contemporánea, 13 (2014), pp. 11-15, cit. pp. 11-12.

12 Contamos con una importante nómina de publicaciones en torno a los cambios producidos en los ayuntamientos a partir de 1814, si bien sería conveniente dirigir una mirada más profunda y diversificada en torno a algunos espacios, particularmente en lo que respecta a los ámbitos rurales. Entre las publicaciones disponibles pueden citarse, a modo de ejemplo: MELÓN JIMÉNEZ, Miguel Ángel: “Oligarquía locales y crisis del Antiguo Régimen en Extremadura”, Investigaciones históricas: Época moderna y contemporánea, 9 (1989), pp. 9-32; CODESAL PÉREZ, Matilde: "Caracteres de la composición del Ayuntamiento absolutista en Zamora (1814-1820): Análisis de los principales cargos”, Studia Zamorensia, 4 (1997), pp. 65-94; LARA LÓPEZ, Emilio Luis: "El sexenio absolutista en Jaén (1814-1820), Boletín del Instituto de Estudios Giennenses, 188 (2004), pp. 319364; SÁNCHEZ CARCELÉN, Antoni: "El retorno al Antiguo Régimen. La restauración absolutista de Fernando VII en Lérida (1814-1820)”, Tiempos Modernos, 28 (2014/1), pp. 1-27; PRADOS GARCÍA, Celia: El gobierno municipal de Granada (1808-1814), Tesis Doctoral, Universidad de Granada, 2015.

${ }^{13}$ Entre las contadas publicaciones que han abordado este fenómeno desde la perspectiva del suroeste cabría destacar el libro de Jacinto de Vega sobre la capital onubense, si bien lo hace desde un enfoque de totalidad y amplitud cronológica que dificultan el análisis en profundidad respecto a los ejes concretos tratados en este artículo. VEGA DOMÍNGUEZ, Jacinto de: Huelva a fines del Antiguo Régimen: 1750-1833, Huelva, Diputación Provincial de Huelva, 1995.
} 


\section{EL REGRESO DE FERNANDO VII: ENTRE LA CELEBRACIÓN DE LA VICTORIA Y LAS EXPECTATIVAS DE CAMBIO}

Los últimos tiempos de la guerra fueron muy reveladores sobre el clima de tensiones y contrariedades que se había abierto entre las filas anti-napoleónicas. El difícil equilibrio que había definido las relaciones entre liberales y absolutista se rompía con el retorno de Fernando VII en 1814. Conforme el monarca se acercaba a la frontera, ambos grupos comenzaron a mover fichas para que el regreso se ajustase a sus ideas e intereses ${ }^{14}$. Las Cortes, instaladas por entonces en Madrid, promulgaron el 2 de febrero un decreto que establecía que Fernando debía jurar la Constitución a su llegada a la frontera para poder ser considerado plenamente libre, y también marcaba el itinerario que debía seguir en su regreso hasta Madrid ${ }^{15}$. Pero el rey, que el 22 de marzo cruzaba la frontera, no siguió el itinerario previsto, sino que, como muestra de su independencia, se detuvo en algunos puntos no recogidos en aquel. En su recorrido fue encontrando además muestras de entusiasmo y exaltación popular que reforzaban su posición frente a la de las Cortes. A su llegada a Valencia se consumaba el conocido golpe de estado: con el apoyo de los "serviles" y su Manifiesto de los Persas ${ }^{16}$, decretaba, con fecha de 4 de mayo, la abolición de la Constitución de 1812 y de la obra de las Cortes, si bien no sería hasta el 11 de ese mes cuando se haría público su contenido, hecho que venía acompañado asimismo por las primeras detenciones de los liberales más destacados. El día 13 de mayo entraba el rey en la capital y recibía un caluroso y exaltado recibimiento por parte del pueblo, cuyo alcance y significado no podrían desprenderse del contexto bélico inmediatamente anterior ${ }^{17}$.

\footnotetext{
14 BUTRÓN PRIDA, Gonzalo: "Redefinir rey y soberanía: el retorno de Fernando VII y la agonía del Liberalismo", Pasado y Memoria. Revista de Historia Contemporánea, 13 (2014), pp. 59-78; RODRÍGUEZ MORÍN, Felipe: "Miedos e ilusiones en la prensa periódica tras el regreso a España de Fernando VII", Rubrica Contemporanea, 8 (2015), pp. 97-115.

15 Para estas cuestiones seguimos a MOLINER PRADA, Antonio: "El retorno de Fernando VII y la restauración de la monarquía absoluta”, en A. Moliner Prada (ed.): La Guerra de la Independencia en España (1818-1814), Barcelona, Nabla, 2007, pp. 575-590; y FRASER, Ronald: La maldita guerra de España. Historia social de la guerra de la Independencia, 1808-1814, Barcelona, Crítica, 2006, pp. 748-752.

16 Según Pérez Garzón, este manifiesto puede ser tomado como el acta de creación del partido absolutista; PERÉZ GARZÓN, Juan Sisinio: Las Cortes de Cádiz. El nacimiento de la nación liberal (1808-1814), Madrid, Síntesis, 2007, p. 406. Un interesante análisis sobre sus supuestos conceptuales en LÓPEZ ALÓS, Javier: "La interpretación patriarcalista de la monarquía absoluta de Fernando VII según «Los Persas»”, Espacio, Tiempo y Forma, Serie V, Historia Contemporánea, 18 (2006), pp. 55-71. Sobre el contexto y sus repercusiones véase BUTRÓN PRIDA, Gonzalo: "El Manifiesto de los Persas. El retorno del rey y el fin de la experiencia constitucional gaditana", Andalucía en la Historia, 44 (2014), pp. 74-77.

17 Para Emilio La Parra, el entusiasmo general y las aclamaciones al rey "no deben ser interpretadas linealmente como un pronunciamiento de la voluntad popular a favor de la monarquía absoluta, sino más bien como la celebración de la victoria y la expresión de júbilo por la restitución de la normalidad, después de una guerra trágica y muy prolongada que todo lo había alterado y en la que se había visto involucrado el conjunto de la población”. LA PARRA, Emilio: “La restauración...”, p. 209.
} 
Estas muestras públicas de regocijo por su regreso también encontraron otros espacios de desarrollo. El caso de la villa de Huelva -sujeta durante los meses de presencia francesa a las dinámicas políticas implementadas por esta y que en la última época había desarrollado un interesante dinamismo al amparo de la nueva normativa emanada de Cádizresultaba muy significativo. Días después de conocerse la llegada del rey a la capital, el ayuntamiento onubense programaba una serie de actos encaminados a la celebración de aquel destacado acontecimiento, que contemplaba la realización de una ceremonia religiosa y la proyección de ciertas acciones festivas en el espacio público de la localidad a partir del mismo aparato visual y sonoro que se había puesto en marcha poco tiempo atrás para la publicación y la jura de la Constitución ${ }^{18}$ :

"En este cavildo se manifestó y dijo por sus mercedes que según los Reales Decretos últimamente comunicados por S. M. el Sr. D. Fernando Séptimo nuestro mui amado y deseado Rey, se halla S. M. en la villa y corte de Madrid libre de su cautividad que ha padecido por el injusto Emperador de los Franceses, y mandando en su Reyno con el acierto y amor que profesa a sus vasallos, y deseando esta villa dar gracias al todo poderoso por el júbilo que ha causado en esta su leal villa su advenimiento al Trono, y dar una prueba de su amor y lealtad determinaron sus mercedes se haga una solemne función en la Parroquia mayor de Sr. San Pedro el día próximo del Sr. San Fernando, en que haya su sermón, se lleve desde esta Casas de Ayuntamiento por el Sr. Alcalde Presidente el retrato de S. M. y se coloque vajo de un docel con toda pompa y aparato en el Presbiterio de dicha Parroquia durante la función, para la que haya tres días de luminarias por la noche, repiques de campana y demás que dé de sí la villa para tan regia función, convidándose todas las autoridades para que sea con más ostentación"19.

La referencia que hacía sobre la libertad de la que ya disponía el rey para mandar en su reino con la clarividencia y el afecto que profesaba a sus "vasallos" resultaba especialmente reveladora sobre los vínculos que se trazaban por entonces entre el fin de la guerra, la victoria ante los franceses y el regreso del monarca, pero asimismo de los pilares sobre los que se sustentaba finalmente la restauración fernandina en relación a la estructura administrativa y política establecida por el liberalismo gaditano. Y en esto último también pueden vislumbrarse algunos de los retos que se abrían para el ayuntamiento a partir de ese momento, particularmente a raíz de la reactivación y la actualización de los compromisos económicos que eran propios del marco político-administrativo del Antiguo Régimen. De

\footnotetext{
18 En otros enclaves del suroeste también se hicieron demostraciones públicas de alegría, aunque no disponemos del relato preciso de su desarrollo. Por ejemplo, en Villanueva de los Castillejos se recogía que "con el correo de hoy ha llegado la plausible noticia de la entrada en España de nuestro amado Rey el Sr. Fernando Séptimo, haciéndose por este Pueblo por tan feliz deseada noticia las mayores demostraciones de júbilo". Archivo Municipal de Villanueva de los Castillejos (en adelante, AMVC). Actas Capitulares, leg. 12, s.f.

${ }^{19}$ Huelva, 24 de mayo de 1814. Archivo Municipal de Huelva (en adelante, AMH). Actas Capitulares, leg. 27, fols. 314-315.
} 
hecho, Ignacio Ordejón, en calidad de administrador de las rentas del marqués de Villafranca, dirigía en el mes de julio un escrito al ayuntamiento de Huelva solicitando el pago de las alcabalas desde el último tercio de 1812 en adelante. En dicho escrito manifestaba significativamente, por un lado, que le era "sumamente sensible" tener que recordar a la corporación el "desprecio ofensivo" con el que había atendido a sus oficios anteriores, "desprecio", repetía, "fundado en el trastorno de las autoridades, bien seguro de que no era fácil encontrar tribunal que le obligase a cumplir sus obligaciones"; y, por otro lado, que la restitución de las facultades de los intendentes le permitía ya en ese momento conseguir el apremio necesario, aunque guiándose por sus principios de moderación, intentaba solucionar este asunto sin elevarlo a la autoridad superior ${ }^{20}$.

Las mismas casas señoriales intentaron capitalizar desde los primeros días las expectativas que se creaban con el regreso del rey y pusieron en marcha un conjunto de medidas que les permitiría recuperar tanto los derechos que les asistían en otros tiempos como su posicionamiento central -también desde el punto de vista público y social- sobre el espacio político y económico que se encontraba tradicionalmente bajo su jurisdicción. Así se desprende, por ejemplo, del poder otorgado en mayo por el marqués de Astorga para atender a la administración de todas sus rentas, posesiones y demás bienes que disponía en el marquesado de Ayamonte ${ }^{21}$.

Los ayuntamientos también se vieron afectados por la eliminación de otras novedades de gobierno y de gestión económica traídas por las Cortes. En este sentido podemos citar, a modo de ejemplo, el acuerdo adoptado por el ayuntamiento de Villanueva de los Castillejos el 15 de mayo de 1814 por el cual, en contraposición a las medidas que había tomado la extinguida cámara gaditana en materia de rentas y posturas, se determinaba reponer "las cosas al modo de ser y estado que tenían antes de tales perjudiciales novedades". Este cambio era interpretado, por tanto, en términos positivos por cuanto venía a reformar una normativa que había provocado "graves perjuicios" a su vecindario, que, como recordaba la misma corporación, "se puso en un continuo clamor y notorio grito por verse tan cargado en la compra de lo necesario para la vida humana",22. En definitiva, lejos de resistirse, las autoridades locales acogieron con expectación y complacencia algunas de las modificaciones que trajo consigo la caída del régimen

\footnotetext{
${ }^{20}$ La Tuta, 22 de julio de 1814. AMH. Actas Capitulares, leg. 27, fol. 261.

21 Ayamonte, 4 de mayo de 1814. Archivo de Protocolos Notariales de Ayamonte. Escribanía de Francisco Javier Granados, Ayamonte, leg. 326, año 1814, fols. 68-69.

22 AMVC. Actas Capitulares, leg. 12, s.f.
} 
constitucional $^{23}$. Otras, en cambio, debieron de resultar más difíciles de asumir, y ello a pesar de las primeras reacciones, ya que si bien la sustitución de los ayuntamientos que regían desde principios de 1814 no generó especiales problemas e inconvenientes, la reimplantación del modelo de dependencia y mediación exterior propició en cambio la apertura de espacios de reclamación y tensión de cierta consistencia y proyección.

\section{LA VUELTA AL AYUNTAMIENTO DE 1808: EL CAMBIO TRANQUILO}

La secuencia de las transformaciones quedaba trazada oficialmente de la siguiente manera. El real decreto de 4 de mayo establecía que los ayuntamientos continuasen en lo político y gubernativo en los términos en los que se encontraban por entonces, hasta tanto no se adoptasen nuevas medidas. Las primeras disposiciones que afectaron a su funcionamiento y organización interna se tomaron a lo largo del siguiente mes. El 15 de junio se establecía que teniendo en cuenta la multitud de atenciones a las que tenían que hacer frente las corporaciones municipales y la imposibilidad de llevarlas a cabo con la exactitud necesaria, debían arreglarse "en el uso de sus facultades económicas y demás que les corresponden a lo prevenido en las leyes que regían en 1808”24. El 25 de junio se disponía la continuidad en ellos de los individuos que entonces los componían, "sin perjuicio de proceder desde luego contra los que resulten criminales", aunque sin poder ejercer otras funciones que las que les eran propias en 1808; al mismo tiempo que se adoptaban además otras medidas que buscaban la desvinculación, también en el plano de la representación y de la construcción del relato, del sistema constitucional. Por ejemplo, mediante el borrado de las actas de elecciones que estaban recogidas en los libros del ayuntamiento, o el cambio en la denominación de los jueces de primera instancia y de partido por los de alcaldes mayores o corregidores $^{25}$.

\footnotetext{
${ }^{23}$ En otros casos se dejaba constancia de la aceptación y conformidad, aunque de manera más aséptica, sin mostrar particular entusiasmo o complicidad por el cambio. Por ejemplo, el ayuntamiento de Huelva manifestaba el 8 de julio de 1814, en relación al cumplimiento del real decreto del 23 de junio sobre rentas por el que se anulaba la disposición de las Cortes del 13 de septiembre anterior, que lo obedecían "con el respeto debido y ceremonias acostumbradas, y en su más exacto cumplimiento mandaron se publique inmediatamente". AMH. Actas Capitulares, leg. 27, fols. 325-328.

${ }^{24}$ Decretos del Rey Don Fernando VII. Año primero de su restitución al trono de las Españas. Se refieren todas las Reales resoluciones generales que se han expedido por diferentes Ministerios y Consejos desde 4 de Mayo de 1814 basta fin de diciembre de igual año. Por D. Fermín Martín de Balmaseda. Tomo I. Madrid, En la Imprenta Real, 1818, p. 74.

25 Decretos del Rey Don Fernando VII..., pp. 94-96. Un análisis más preciso en torno a los recursos propagandísticos utilizados tras la vuelta de Fernando VII para imponer una determinada visión de los acontecimientos de los últimos tiempos en CALVO MATURANA, Antonio: "Como si no hubiesen pasado jamás tales actos': La gestión fernandina de la memoria histórica durante el sexenio absolutista (1814-1820)”, en E. García Monerris, M. Moreno Seco y J. I. Marcuello Benedicto (eds.), Culturas políticas monárquicas en la España liberal. Discursos, representaciones y prácticas (1808-1902), Valencia, Universidad de Valencia, 2013, pp. 3157.
} 
No obstante, no sería sino hasta finales de julio cuando se acometiese el cambio definitivo. El real decreto del 30 de ese mes, que partía de la "necesidad de dictar providencias que alcanzasen a cortar los graves males y daños del trastorno general padecido en la administración de justicia y en el gobierno interior de los pueblos con motivo de las nuevas instituciones", establecía la disolución y extinción de los ayuntamientos y alcaldes llamados constitucionales y el restablecimiento de los existentes en 1808 “sin novedad ni alteración alguna en cuanto a la denominación, número, calidades y funciones de los oficios y empleados de que entonces constaban", así como el restablecimiento de los corregimientos y alcaldías mayores según el estado que tenían en ese mismo año ${ }^{26}$.

Ahora bien, la restauración de cargos e instituciones no se podía llevar a cabo sin tener en cuenta la realidad concreta de 1814, lo que se tradujo en la ocupación por parte de la corona de ciertos campos de gestión política que se encontraban con anterioridad en manos de las respectivas casas señoriales: no en vano, en el artículo octavo se recogía que "sin perjuicio de lo que a su tiempo se resuelva en el expediente sobre el decreto de las Cortes en punto a señoríos particulares", el rey se reservaba "por ahora el nombramiento a consulta de la Cámara de los Corregidores y Alcaldes mayores en los pueblos de señorío que antes los tenían"; y en el noveno que "bajo la misma calidad de por ahora encargo a mis Chancillerías y Audiencias del reino la confirmación de los oficios de república en los pueblos de Señorío y Abadengo de sus respectivos territorios, en vista de las propuestas o nombramientos que estos deberán dirigirle para el reemplazo de las vacantes" ${ }^{27}$. En definitiva, ordenada la vuelta al modelo de ayuntamiento del Antiguo Régimen con el importante matiz señalado de la irrupción de la corona en las atribuciones de los señores, y trazado el procedimiento que debía seguirse, lo único que faltaba para que el cambio se hiciese efectivo era la aplicación práctica de la normativa por parte de aquellas autoridades locales que tenían un origen constitucional y que debían ser reemplazadas en sus tareas de gobierno.

Los distintos pueblos del suroeste conocerían el contenido de los decretos algunos días después de su promulgación. Por ejemplo, a mediados de julio el ayuntamiento de Gibraleón conferenciaba sobre la real cédula de 25 de junio anterior y acordaba, haciendo una interpretación amplia de su tenor bajo el argumento de dejar "testimonio de su obediencia, sumisión y amor a nuestro idolatrado y suspirado monarca el Sr. D. Fernando Séptimo", el borrado no solo de las actas de elecciones contenidas en el libro capitular, sino

${ }^{26}$ Decretos del Rey Don Fernando VII..., pp. 149-153.

${ }^{27}$ Ibidem. 
del propio término "constitucional" en todas aquellas ocasiones en las que se repitiese a lo largo del mismo ${ }^{28}$.

A diferencia de lo ocurrido en otros puntos de la Península, en los pueblos del suroeste estudiados no se generaron acciones inmediatas y violentas contra el orden constitucional $^{29}$. La extinción de esos ayuntamientos constitucionales se producía a finales de agosto, una vez recibida la disposición del 30 del mes anterior que marcaba el proceso a seguir. En El Almendro y Villanueva de los Castillejos había sido recibida el 26 de agosto y al siguiente día se llevaba a cabo su cumplimiento. En Huelva y Cartaya se puso en marcha el auto de obedecimiento y cumplimiento el día 30, y en Gibraleón el 31. En todos estos enclaves se recibía y aplicaba con el respeto y la obediencia que cabía esperar, lo que llegó incluso a acompañarse de una determinada ritualidad que no hacía sino subrayar la trascendencia del momento. Tal fue el caso de Villanueva de los Castillejos, donde una vez vista la real cédula por los miembros de la corporación, "la tomaron en sus manos, besaron y pusieron sobre sus cabezas, como carta de su Rey y Señor natural, diciendo la obedecían y obedecen con el más profundo respeto" ${ }^{30}$.

La reposición de los capitulares de 1808 no generó tampoco resistencias significativas más allá de alguna moción centrada en el retorno concreto de un individuo. En el caso de Huelva algunos de los componentes del ayuntamiento saliente llegaron a protestar por la vuelta de Francisco de Mora al puesto de alcalde bajo el argumento de que había ejercido como depositario de propios en 1809 y alcalde constitucional en 1812 y 1813, y que no había aún rendido las cuentas correspondientes a ambos periodos ${ }^{31}$. Con

\footnotetext{
28 Sesión de 16 de julio de 1814. Archivo Municipal de Gibraleón (en adelante, AMG). Actas Capitulares, leg. 14 , s.f.

29 Algunos ejemplos localizados en distintos puntos de la Península dan buena cuenta de la proyección y alcance de ciertas acciones en los primeros momentos en contra de los ayuntamientos entonces existentes o sobre los símbolos del nuevo tiempo traído por la Constitución. En Zamora se producía el 14 de mayo, tras una revuelta popular, la destitución del ayuntamiento constitucional vigente, si bien habría que esperar al 8 de agosto para la resolución definitiva del cambio, hasta tanto no se acogiese el proceso al sistema arbitrado por la real cédula de 30 de julio. Algo muy parecido ocurrió en Granada, donde el 17 de mayo la multitud además de destruir y quemar la placa de la Plaza de la Constitución y algunos ejemplares de esta, impulsaría la extinción del ayuntamiento constitucional, aunque no sería hasta el 10 de agosto cuando tuviese lugar la primera reunión de la nueva corporación. En Jaén el 6 de mayo se asistiría a la circularon de pasquines anticonstitucionales y a un acto vandálico contra la lápida conmemorativa de la Constitución, clima de tensión que conduciría el 11 de mayo a la extinción del ayuntamiento constitucional y a la vuelta a la situación política local de 1808. En Badajoz y Cáceres también se produjeron altercados en los días siguientes al real decreto del 4 de mayo: en el primer caso un conjunto de vecinos cambiaría el nombre de la Plaza de la Constitución por el de Plaza de San Fernando, "profiriendo diversas expresiones contra la constitución"; y en el segundo se promovió un gran alboroto que conduciría a la quema de ejemplares de la Constitución en medio de la plaza y a la aclamación como alcalde del Conde de Mayoralgo. CODESAL PÉREZ, Matilde: "Caracteres de la composición..."; LARA LÓPEZ, Emilio Luis: "El sexenio absolutista...”, pp. 327-332; MELÓN JIMÉNEZ, Miguel Ángel: “Oligarquía locales...”, p. 30; PRADOS GARCÍA, Celia: El gobierno municipal de Granada...

30 Auto de obedecimiento y cumplimiento, 27 de agosto de 1814. AMVC. Actas Capitulares, leg. 12, s.f.

31 Sesión de 31 de agosto de 1814. AMH. Actas Capitulares, leg. 27, fols. 333-334.
} 
todo, esta reclamación no impidió la automática reincorporación de ese sujeto al cuadro de gobierno restaurado, como queda patente con su participación en la primera reunión celebrada al día siguiente de su constitución ${ }^{32}$.

Los mayores problemas se derivaron de la ausencia de algunos de los capitulares de 1808, ya sea por fallecimiento, inhabilitación o desavecindamiento. Por ejemplo, en Gibraleón se tuvo que designar a un nuevo diputado - encargo que recaería ahora en la persona que había obtenido la pluralidad de votos en 1808 por detrás del que resultó finalmente titular- por quedar inhabilitado el que ejerció al haber pasado al estado eclesiástico $^{33}$, circunstancia que obligaría finalmente a elevar una consulta a la Real Audiencia de Sevilla sobre la posible incompatibilidad que se generaba con este hecho en relación al parentesco entre dos de sus miembros ${ }^{34}$.

En Villanueva de los Castillejos el cuadro de gobierno de 1808 había quedado muy mermado tanto por el avecindamiento en otros pueblos del entorno de algunos de sus miembros como por el fallecimiento de otros. Con todo, los capitulares disponibles tomaban de inmediato las riendas de la corporación, acabando así con "la interinidad del Ayuntamiento que fue creado por la constitución abolida en esta parte, y en todo lo que fue opresiva a la soberanía fue efectivamente remplazados en las insignias de Justicia, posesión de asientos, Jurisdicción, votos y gobierno municipal" ${ }^{35}$. No obstante, las vacantes no se ocuparon hasta algún tiempo después, ya que la propuesta realizada por los recién incorporados no se ajustaba a derecho y hubo que esperar a que la Audiencia de Sevilla, con fecha de 17 de octubre, librase una provisión instando a que la misma fuese realizada por los capitulares de 1807. No sería hasta el 21 de noviembre, una vez remitida la proposición, cuando la institución sevillana designaba a los nuevos miembros ${ }^{36}$.

En El Almendro, además de la emigración a Portugal o el fallecimiento, se aducirían motivos médicos para justificar la no incorporación de algún miembro ${ }^{37}$. Esta última circunstancia también provocaría algún contratiempo en Cartaya, si bien sería circunstancial y se resolvería con celeridad ${ }^{38}$.

Ahora bien, más allá de los cargos de renovación anual, en algunos pueblos existían puestos que se vinculaban a una persona en concreto y que, por tanto, no estaban

\footnotetext{
32 Sesión de 1 de septiembre de 1814. AMH. Actas Capitulares, leg. 27, fols. 334-335.

${ }^{33}$ Sesión de 1 de septiembre de 1814. AMG. Actas Capitulares, leg. 14, s.f.

34 AMG. Actas Capitulares, leg. 14, s.f.

35 Sesión de 27 de agosto de 1814. AMVC. Actas Capitulares, leg. 12, s.f.

${ }^{36}$ La proposición de los capitulares de 1807 tiene fecha de 24 de octubre, y el recibimiento y la posesión de los nuevos miembros se producían el 27 de noviembre. AMVC. Actas Capitulares, leg. 12, s.f.

37 Documentos de 28 de agosto, 10 de septiembre y 22 de octubre de 1814. Archivo Municipal de El Almendro (en adelante, AMEA). Actas Capitulares, leg. 4, s.f.

38 AMC. Actas Capitulares, leg. 9, s.f.
} 
sujetos al proceso de reemplazo. En estos casos se generaron algunos problemas y dudas iniciales que se resolverían según el criterio, ajustado a lo marcado por la normativa al uso, de la Audiencia de Sevilla. Por ejemplo, este tribunal remitía una orden al ayuntamiento de Gibraleón con fecha de 10 de septiembre para que tomase también posesión, siguiendo el artículo tercero de la real cédula de 30 de julio, de los oficios supernumerarios de alguacil mayor y alcaides de palacio y de la mar en los términos que lo fueron en 1808, hecho que finalmente se produjo el 19 de ese mismo mes $^{39}$. En Cartaya, sin embargo, la situación resultaba bien distinta. El mismo tribunal territorial de Sevilla tuvo que conferenciar en octubre sobre el recurso instruido por José Antonio Benítez relativo a su restitución en el empleo de alcaide de la mar, aunque en este caso resolvía, acogiéndose a lo contenido en la real cédula de 15 de septiembre último ${ }^{40}$, que había quedado extinguido su privilegio y, en consecuencia, no debía reintegrarse a la corporación ${ }^{41}$. Otros ejemplos situados fuera del suroeste venían a incidir precisamente en las dificultades que encontraba la restitución del cuadro completo de gobierno municipal, circunstancia que quedaba marcada en última instancia por el rebrote de la lucha entre las oligarquías y las tensiones generadas internamente entre los miembros del cabido ${ }^{42}$.

\section{LA RESTITUCIÓN DEL MARCO SEÑORIAL: LOS LÍMITES DEL CAMBIO}

Junto a los cambios en el organigrama interno de los ayuntamientos, se asistió a la recuperación de los tradicionales mecanismos de articulación entre comunidades locales que compartían un mismo espacio jurisdiccional. En este contexto puede referirse, por ejemplo, la recuperación del papel protagonista que había ejercido tradicionalmente el ayuntamiento de Gibraleón sobre los campos del marquesado. No en vano, a raíz de su denuncia en torno a "que el desorden introdusido en la triste pasada época ha dado margen a la destrucción de los arbolados, así en las dehesas de esta villa como en los campos valdíos de su jurisdicción, pues que desconosida o usurpada la Jurisdicción que esta villa tiene ejecutoriada por las de los pueblos de este partido, sus vecindarios han cometido

\footnotetext{
39 AMG. Actas Capitulares, leg. 14, s.f.

${ }^{40}$ Decretos del Rey Don Fernando VII..., pp. 251-253.

${ }^{41}$ Sevilla, 7 de octubre de 1814. AMC. Actas Capitulares, leg. 9, s.f.

42 Como sostiene Ramón Cózar para el caso de Albacete, el intento orquestado a finales de 1814 por Luis Roca Togores, Conde de Pino Hermoso, para obtener el oficio de alférez mayor según le era propio a su familia no obtuvo el fruto esperado debido a la resistencia de uno de los regidores presentes en la petición de informes por el Consejo. Dicho regidor justificaba su disconformidad en base a la conducta moral y las sospechosas actuaciones del referido Conde en el servicio a la patria y a la Corona durante el tiempo del "intruso rey José". CÓZAR, Ramón: "La descomposición del municipio del Antiguo Régimen. Los últimos regidores perpetuos de la villa de Albacete", Tiempos Modernos, 19 (2009/2), pp. 1-42, cit. p. 22.
} 
impunemente toda clase de exesos"; y del contenido del real decreto de 30 de julio sobre la recuperación de sus antiguas atribuciones, asumía nuevamente el cuidado y conservación de los montes y arbolados, y prevenía de forma expresa a los guardas que celasen con energía los campos comunes y denunciasen cualquier exceso que advirtiesen en los mismos ${ }^{43}$. El cabildo olontense también pondría especial interés en recuperar su tradicional espacio en materia judicial.

En este contexto, el repuesto regidor decano de Gibraleón, Antonio Íñiguez, se dirigía al ayuntamiento de Villanueva de los Castillejos en septiembre de 1814 manifestando que habiendo sido restituida la jurisdicción ordinaria de su villa y su partido "al antiguo goce de las prerrogativas que entonces tenía, en que ha sido inquietada por el trastorno y confusión de la pasada época, le corresponde el conocimiento privativo en los campos comunes de este partido", por lo que reclamaba la remisión de todas las causas criminales al juzgado que encabezaba, "único competente con arreglo a las Reales Executorias" 44.

Pese al restablecimiento de algunos mecanismos de relación intercomunitaria que descansaban en el marco señorial tal cual se encontraba al inicio de la guerra, no se recuperó sin embargo la antigua preeminencia de las casas señoriales en la conformación de las autoridades a nivel municipal. De hecho, la Audiencia territorial de Sevilla sería la encargada de articular los procesos de cambio y renovación política de los distintos pueblos del suroeste tanto en el episodio iniciado en los últimos días de agosto como también a finales de año, cuando correspondía llevar a cabo la designación por vía ordinaria de los sujetos que debían estar al frente de los diferentes ayuntamientos a lo largo de 1815.

En efecto, en diciembre de 1814 los distintos cabildos fueron componiendo las proposiciones -como se recogía en la reunión montada para ello en Gibraleón, "según como se hacía para remitir a la Excma. Sra. Duquesa de Béjar, Jurisdiccional que era de esta Villa" ${ }^{45}$ - y remitiéndolas al tribunal territorial, quien finalmente seleccionaba, en nombre del rey, a los individuos que ingresarían en el ayuntamiento del siguiente año. Todos los casos analizados se ajustaron a este esquema, si bien en El Almendro los distintos momentos del proceso se implementaron más tardíamente ${ }^{46}$. Y en todos se hicieron, además, sin sobresaltos ni estridencias palpables, aunque es cierto que en algún caso se llegaba a vislumbrar un clima no tan apacible ni pacífico como cabría sostener a primera vista.

\footnotetext{
${ }^{43}$ Gibraleón, 2 de septiembre de 1814. AMG. Actas Capitulares, leg. 14, s.f.

${ }^{44}$ Gibraleón, 5 de septiembre de 1814. AMVC. Actas Capitulares, leg. 12, s.f.

45 Propuesta de capitulares y demás oficios de república, 28 de diciembre de 1814. AMG. Actas Capitulares, leg. 14, s.f.

46 Como se recogía en un acuerdo adoptado el 4 de mayo de 1815, la noche anterior fueron recibidos y posesionados en sus respectivos empleos conforme a la Real Provisión "que se recibió con notable atraso de correo ignorándose el motivo". AMEA. Actas Capitulares, leg. 4, s.f.
} 
Motivada por la representación hecha por el ayuntamiento de Huelva sobre las dificultades que encontraba para celebrar el cabildo de elecciones de justicias y capitulares para el siguiente año, la Audiencia de Sevilla enviaba una providencia por la cual instaba a que elaborase la propuesta correspondiente con arreglo a las leyes e instrucciones de la materia, pero "sin promover consultas impertinentes" 47 . Con todo, lo más sorprendente sería la reacción del mismo cabildo onubense, toda vez que refería no haber elevado a la superioridad ninguna representación sobre esa materia, de ahí su protesta e intento por averiguar a nombre de quién y por quién se había hecho esa consulta por la que había recaído el referido apercibimiento ${ }^{48}$.

La clave de este episodio podría encontrarse en el clima de tensiones que se había manifestado abiertamente en Huelva durante la etapa constitucional, de la que quedarían no pocos rescoldos que podrían explicar ciertas operaciones de movilización y proyección pública por parte de algunos individuos o grupos socio-profesionales que querían contar con mayores cotas de participación y protagonismo en los renovados instrumentos de poder municipales. Es decir, la representación pudo ser hecha por sujetos ajenos entonces al cabildo pero que contaban con cierta presencia y proyección anterior -no necesariamente en el escenario público más visible-, y cuya intención sería la de buscar algunos resquicios o espacios de participación que les permitiesen alcanzar un mejor posicionamiento y capacidad de acción dentro del marco general -exclusivo y excluyenteque se había establecido tras la restauración fernandina. Pero si este incidente entre bambalinas no puede sino plantearse en el terreno exclusivo de la hipótesis, otros episodios adoptaron en cambio un ámbito de desarrollo más abierto y diáfano, y permiten, por tanto, un análisis más completo.

El ayuntamiento de Cartaya había puesto especial atención durante la etapa constitucional en desactivar todos los elementos que aún recordaban al asimétrico y jerárquico marco señorial extinto, que privilegiaba a la villa de Gibraleón frente al resto de participantes en el marquesado. Los cambios abiertos en 1814 no ahogaron, sin embargo, estas tendencias articuladoras de esencia igualitarista y equilibrada, que encontraban ahora amparo en un modelo de restauración que había restringido el campo de acción de los antiguos señoríos jurisdiccionales y asegurado la proyección de las instituciones realengas sobre espacios antes sujetos a los mismos. En líneas generales, el juego de permanencias y cambios no haría sino posibilitar la apertura de espacios de confrontación, toda vez que

\footnotetext{
${ }^{47}$ Acuerdo adoptado el 9 de diciembre de 1814. El documento que se remitía a Huelva contaba con fecha de 17 de diciembre. AMH. Actas Capitulares, leg. 27, fol. 342.

48 Sesión de 23 de diciembre de 1814. AMH. Actas Capitulares, leg. 27, fol. 343.
} 
propiciaba lecturas diferentes en función de los intereses defendidos por unos y otros. Por ejemplo, el nombramiento efectuado en marzo de 1815 de José Barragán como corregidor de Gibraleón provocaría el choque entre éste -apoyado, como cabe suponer, por las autoridades locales olontenses- y el ayuntamiento de Cartaya por la definición de su área precisa de actuación, toda vez que este último defendía su independencia y separación respecto al marco potestativo representado por aquel bajo el argumento principal de formar parte de la nómina de villas exentas con jurisdicción real ordinaria, y de contar asimismo con una figura política que demostraba y garantizaba su exención y soberanía jurisdiccional:

"Y habida consideración a que según el literal contexto de dicha Real Cédula sólo se agracia al Sr. interesado para el citado corregimiento de Gibraleón [...], sin hacer extensivo dicho nombramiento a esta de Cartaya baxo boz ni denominación alguna especifica ni general, puesto que la de Gibraleón y su tierra quando más podrá ampliarse a los Pueblos Pedáneos de su Distrito. Que lejos de serlo esta dicha Villa, lo es de las exentas con Jurisdicción Real Ordinaria que han regentado de muchos años a esta parte sus respectivos corregidores baxo el impropio nombre de tenientes, que les libraban los señores territoriales apoyados en sus privilegios exclusivos en que hoy y por ahora se hallan suspensos por Novísima Real Orden, y según la qual y posteriores informes debe esperarse de un momento a otro su Corregidor respectivo que con total independencia de Gibraleón regente dicha su Real Jurisdicción como lo han hecho y hace a su nombre en el día su Regidor Decano. Dixeron, debían de acordar y acordaron no haber lugar por los fundamentos expuestos a tener ni reputar extensiva dicha Real gracia a esta Villa eximida, al menos en el ínterin que por S. M. otra cosa en expreso se decrete, a cuya soberana determinación prestarán la ciega obediencia" 49 .

Este contencioso se extendería durante algún tiempo, asistiéndose en su desarrollo a algunos cambios e iniciativas políticas que condicionarían el resultado del mismo. El nombramiento del alcalde mayor, un hecho clave para entender el desarrollo del litigio, se produjo entre la representación que el ayuntamiento de Cartaya elevó al rey a mediados de julio, que contenía las razones que le habían llevado a impulsar "su justa queja y fundamentos que versan para su denegación" 50 , y la decisión adoptada por el Consejo a finales de noviembre, una vez calibrados los testimonios aportados por el cabildo y el corregidor, que establecía que se cumpliese y guardase lo recogido en el título expedido a favor del referido corregidor en los términos que lo ejercieron sus antecesores hasta $1808^{51}$. Como aparecía recogido en el acta del 12 de julio, en esa fecha estaba aún pendiente la designación por la autoridad real de la antigua figura del teniente corregidor, siendo en agosto cuando se producía su nombramiento -aunque utilizando la fórmula nominal, al

\footnotetext{
${ }^{49}$ La real cédula sobre el nombramiento está expedida en palacio a 21 de marzo de 1815. La sesión que recoge el intento de recibimiento y donde se manifiesta la resistencia al mismo tiene fecha de 12 de julio de ese mismo año. AMC. Actas Capitulares, leg. 9, año 1815, fols. 6-7.

50 Acuerdo tomado el 14 de julio. AMC. Actas Capitulares, leg. 9, año 1815, fols. 8-9.

${ }^{51}$ Madrid, 30 de noviembre. AMC. Actas Capitulares, leg. 9, año 1815, fol. 22.
} 
igual que ocurría en otros pueblos del entorno, del alcalde mayor-, y en octubre cuando se asistía a su recibimiento por el ayuntamiento ${ }^{52}$. La entrada de Joaquín Fernández Durán en el puesto de alcalde mayor, que le permitía ejercer además como presidente de la corporación, iba a imposibilitar la inmediata aplicación del acuerdo del Consejo del 30 de noviembre sobre el recibimiento del corregidor de Gibraleón, ya que si bien el resto de miembros del cabildo de Cartaya aceptaba ahora su recepción, la protesta que hacía el alcalde mayor por los perjuicios que ello suponía para su encargo ${ }^{53}$ y la no participación en el acto de recibimiento anulaban todo el proceso, ya que el cuadro de gobierno resultante carecía de la real jurisdicción necesaria para ello:

"Juntos los mismos Sres. del Ayuntamiento se hizo presente a sus mercedes por el Sr. Presidente un oficio del Cavallero Corregidor de la Villa de Gibraleón en el que manifiesta hallarse en ésta con objeto a tomar la posesión decretada por El Supremo Consejo en el Real decreto que antecede, y enterados sus mercedes, tratando cumplir lo prebenido en el mismo y que tienen acordado, mandaron se pase desde luego al recebimiento del referido Cavallero Corregidor de Gibraleón. En este acto dixo el Sr. Presidente y Alcalde Mayor de esta Villa, que de modo alguno concurría al recebimiento; y reconvenido por los Sres. del Ayuntamiento, como habían de dar la posesión acordada no presentándose dicho Sr. Presidente a su concurrencia, respondió que se retiraba y que los Sres. del Ayuntamiento hiciesen lo que tubiesen por conveniente, quedando en libertad para ello [...]. En este estado, acordaron los Sres. del Ayuntamiento pasase una Diputación del mismo acompañada del Alguacil Mayor para que acompañase al expresado Cavallero Corregidor de Gibraleón de las casas donde se halla, a las Capitulares [...]; y habiéndose presentado el mismo Cavallero Corregidor, tratando sus mercedes darle la posesión dixo: Que mediante a considerar que la falta de Presidente de que carece en la actualidad el Ayuntamiento, aunque manifiesta los buenos deseos de éste, hace nulo quanto se obre, pues en ninguno de los actuales capitulares reside la Real Jurisdicción de que a su merced se debe aposesionar, cree no debe prestarse a lo que el Ayuntamiento determina sin que este se halle con Juez y Presidente a su Cabeza, por lo que se concluyó este acto que firmaron sus mercedes y dicho Cavallero Corregidor de Gibraleón" ${ }^{54}$.

Este hecho ponía en una situación muy comprometida a la corporación y propiciaba una fractura entre el alcalde mayor y el resto de componentes, como quedaba de manifiesto en el acuerdo del 20 de diciembre que instaba al primero a que pagase en el término máximo de seis días la fianza que aún tenía pendiente por la ocupación de su empleo, si bien éste se comprometía a hacerlo en el plazo de quince días ${ }^{55}$. Finalmente, la Audiencia de Sevilla disponía con fecha de 13 de enero de 1816 y bajo amenaza de multa, que el alcalde mayor reuniese al ayuntamiento para dar posesión al corregidor de Gibraleón,

\footnotetext{
${ }^{52}$ La real cédula de concesión fue dada en palacio el 10 de agosto de 1815 . El acuerdo para recibir al alcalde mayor se llevó a cabo el 17 de octubre de ese mismo año. AMC. Actas Capitulares, leg. 9, año 1815, fol. 15.

${ }^{53}$ Sesión de 20 de diciembre de 1815. AMC. Actas Capitulares, leg. 9, año 1815, fols. 24-25.

${ }^{54}$ AMC. Actas Capitulares, leg. 9, año 1815, fols. 25-26.

55 AMC. Actas Capitulares, leg. 9, año 1815, fols. 27-28.
} 
hecho que se llevó a cabo al siguiente día, momento en el que se le situaba en el "lugar y asiento superior que le corresponde" 56 .

En cierta manera, esta disputa venía a confirmar los diferentes intereses puestos en juego dentro del propio ayuntamiento. Por un lado, entre los cargos que debían su nombramiento a las autoridades superiores y que, dados los beneficios económicos y políticos que sacaban de ello, se enfrentaron por la defensa de su empleo y la definición de su campo de actuación. Por otro, entre los miembros adscritos directamente a la comunidad local, los cuales, una vez que tenían que aceptar -según disposición de la corona- la presencia de componentes venidos de fuera y nombrados por agentes externos ${ }^{57}$, no debieron de encontrar mucha diferencia en tener a su frente a uno o dos de esos individuos. En la práctica, ambos representaban el mantenimiento de líneas tradicionales de observación y control, aunque el origen del nombramiento se situase ya al margen de la casa de Béjar, de ahí su distancia en relación a la segunda vía de reclamación abierta por el alcalde mayor, no así sobre la primera, momento en el que elevaron una protesta con anterioridad incluso al nombramiento de este último.

Resulta probable además que ese distanciamiento estuviese conectado con una importante solicitud que los capitulares habían remitido al monarca en el mes de julio, tras haber interpuesto recurso sobre el recibimiento del corregidor de Gibraleón, pero algún tiempo antes del nombramiento e incorporación del alcalde mayor. El ayuntamiento de Cartaya, compuesto todavía de forma exclusiva por sujetos salidos de su comunidad local, acordaba con fecha de 15 de julio elevar una propuesta a la corte para que se admitiese el nombramiento de dos alcaldes ordinarios siguiendo la práctica observada en el pueblo desde el tiempo de su conquista hasta el año 1657 y que, tras haber sido reconocida por resolución del Consejo de fecha de 20 de noviembre de 1811 a petición de la corporación, había vuelto a experimentarse en la conformación del ayuntamiento de $1812^{58}$. Como cabe suponer, esa práctica afectaría a la modificación del cuadro de gobierno municipal con la incorporación de los dos alcaldes ordinarios, pero también debía de tener repercusiones sobre el proceso de elección de los mismos, cuyo sistema podría tener ciertas conexiones además con la fórmula desarrollada durante la etapa constitucional, si bien es cierto que la

\footnotetext{
56 AMC. Actas Capitulares, leg. 9, año 1816, fols. 10-17.

${ }^{57}$ Contamos con otros ejemplos sobre las resistencias de las élites locales respecto a la admisión en el poder municipal de una persona venida de fuera e impuesta. Así ocurrió en el cabildo jiennense en septiembre de 1814, cuando el Comandante de Armas del Reino de Jaén, Carlos Carabantes, fue nombrado corregidor interino de la ciudad. El ayuntamiento se negaría "con un empecinamiento extraordinario" a la aceptación de dicha decisión gubernativa. LARA LÓPEZ, Emilio Luis: “El sexenio absolutista...”, p. 344.

58 AMC. Actas Capitulares, leg. 9, año 1815, fol. 10.
} 
construcción del relato obviaba la referencia a ese tiempo denostado por los valedores de la restauración fernandina.

Este último aspecto pudo estar en la base del acuerdo adoptado, primero por los miembros del ayuntamiento y después por la comunidad local reunida en un cabildo general, por el que la villa no solo cedía "las cantidades ya liquidadas pendientes a beneficio de la Corona y actuales urgencias del Estado", renunciando a cualquier reclamación futura, sino que lo hacía mediante una profesión expresa de su lealtad política al monarca absoluto, al que atestiguaba el "amor y ferviente zelo" que le profesaban ${ }^{59}$. Esta iniciativa podría responder a una estrategia orquestada desde dentro de la comunidad para desactivar las posibles reticencias que pudiesen surgir en la corte a raíz de una solicitud que iba a contra mano de los cánones marcados tras la vuelta de Fernando VII, facilitando así, una vez estampados de forma nítida la adhesión y el apego a la figura del monarca, la aprobación de una solicitud sobre la que tendría puestas ciertas expectativas y anhelos en relación a su capacitación y autonomía política. No en vano, en el acto de recibimiento del alcalde mayor del 17 de octubre no se explicitaba ningún movimiento de resistencia, si bien reconocía que se llevaba a cabo sin perjuicio del recurso que tenía pendiente sobre la aprobación del nombramiento de alcaldes ordinarios que le fue concedido en noviembre de $1811^{60}$.

\section{CONSIDERACIONES FINALES}

La restauración fernandina en el suroeste andaluz presentaba rasgos heterogéneos y recorridos diferentes, si bien en conjunto pueden trazarse algunas líneas generales de actuación. El regreso de Fernando VII provocaría, al igual que en otros lugares de la Península, muestras de júbilo, pero sin las acciones violentas contra la Constitución, sus símbolos o valedores que se habían dado en otros casos. $\mathrm{Y}$ aunque esas expresiones de regocijo solo quedan constatadas documentalmente para los casos de Huelva y Villanueva de los Castillejos, debieron de ocupar también, de manera más o menos espontánea o sistematizada, un espacio importante en el resto de pueblos del entorno. No hay que obviar la identificación que se haría entonces entre el regreso del rey cautivo con la celebración de la victoria, la superación de la guerra y la vuelta a la normalidad. Y todo ello pasado por el tamiz específico que proporcionaba la experiencia de la guerra en el suroeste, caracterizada

\footnotetext{
${ }^{59}$ La reunión del cabildo tiene fecha de 17 de agosto. El cabildo general abierto que trató sobre este mismo particular se desarrolló el 20 de ese mes y contó con la presencia de los miembros del ayuntamiento, "juntos con el más numeroso concurso que se personaron a la celebración de este acta". AMC. Actas Capitulares, leg. 9, año 1815, fols. 11-13.

60 AMC. Actas Capitulares, leg. 9, año 1815, fol. 15.
} 
por su situación fronteriza -en su versión tanto tradicional de separación de los dos reinos peninsulares como novedosa de división entre las tierras ocupadas por los franceses y las que estaban al margen del control directo de estos- y por su posicionamiento central en la vanguardia de la lucha en algunos momentos de la misma.

Los primeros momentos también vislumbraron transformaciones de importancia en el ámbito impositivo y de la gestión de los recursos, generando en algún ayuntamiento ciertas expectativas y complacencias por el resguardo de los intereses que los cambios traían para su comunidad. Por su parte, la sustitución de los ayuntamientos que regían desde principios de 1814 no generó en conjunto especiales problemas e inconvenientes, mientras que la reimplantación del modelo de dependencia y mediación exterior propició en cambio la apertura de espacios de reclamación y tensión de cierta consistencia y proyección. De la misma forma, a pesar de que la elección para 1815 se efectuó en todos los enclaves sin sobresaltos ni estridencias palpables, no se puede obviar que en algún caso se llegaba a vislumbrar un clima no tan apacible ni pacífico como cabría sostener a primera vista. En este escenario habría que situar los ejemplos de Huelva, cuyo ayuntamiento llegaba a recibir un escrito desde Sevilla que censuraba la remisión de una consulta impertinente, o el de Cartaya, que además de mostrar cierta resistencia por la reinstauración del corregidor y el alcalde mayor, manifestaba su interés por contar a su frente, a diferencia de lo que marcaba su cuadro de gobierno tradicional, con las figuras de dos alcaldes.

En definitiva, no parece que la restauración fernandina en las tierras del suroeste pudiese abstraerse de los profundos cambios operados durante la Guerra de la Independencia, por lo que se vería obligada a asumir, al menos en parte, el reajuste políticosocial y el nuevo equilibrio de fuerzas generado a lo largo de aquellos trascendentales años. En cierta manera, según sostiene Moliner Prada, no fue posible entonces la vuelta al antiguo modelo social, ni resultó sencillo el regreso a la normalidad prebélica ${ }^{61}$. La trascendencia de los cambios operados a partir de 1808 iba a dejar una profunda huella en las distintas comunidades locales del suroeste, si bien es cierto que resulta necesario un análisis más extenso y sistemático para calibrar su verdadera dimensión ${ }^{62}$.

\footnotetext{
${ }^{61}$ MOLINER PRADA, Antonio: “El retorno de Fernando VII...”, p. 589.

${ }^{62}$ Un análisis más completo sobre los seis años de restauración absolutista permitiría confrontar, entre otras cuestiones, la realidad socio-política del suroeste en relación a otros escenarios ya estudiados, sobre su grado de desajuste o correspondencia. Por ejemplo, respecto a lo marcado para el caso de Lérida, donde si bien es cierto que la oligarquía más conservadora dominaría los principales cargos municipales, no puede obviarse que también accedieron a los cargos electos sectores más populares o más proclives al liberalismo, como quedaba patente por el acta del ayuntamiento de noviembre de 1823 al referir que los diputados elegidos para el año 1816 fueron "adictos al sistema constitucional y revolucionario de una manera notoria". SÁNCHEZ CARCELÉN, Antoni: “El retorno al Antiguo Régimen...”, pp. 11-13.
} 